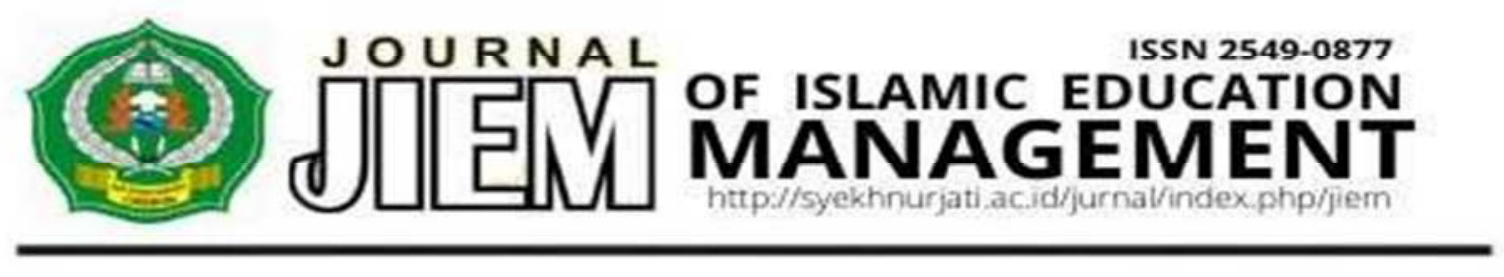

\title{
IMPLEMENTASI SISTEM PENJAMINAN MUTU EKSTERNAL DI SEKOLAH DASAR ISLAM TERPADU SABILUL HUDA
}

\author{
IMPLEMENTATION OF EXTERNAL QUALITY ASSURANCE SYSTEM \\ IN SABILUL HUDA INTEGRATED ISLAMIC PRIMARY SCHOOL
}

\author{
Ali Hasan \\ Institut Agama Islam Negeri (IAIN) Syekh Nurjati Cirebon \\ alihasan@syekhnurjati.ac.id
}

\begin{abstract}
The This study aimed to reveal in depth about the application of external quality assurance Sabilul Huda Integrated Islamic Primary School (SHIIPS). This study used a descriptive qualitative approach. The technique of collecting data was triangulation. Data analysis was inductive in nature, external quality assurance in detail and accurately through the results of data derived from written data and documentation and oral interviews from related people. The results showed that the application of external quality assurance at SHIIPS can be categorized quite well, namely on graduate competency standards, curriculum content standards, process standards, educators and teaching staff standards, facilities and infrastructure standards, teaching unit management standards, education financing standards and grading standard
\end{abstract}

Keywords : quality standards, assessment, external

\begin{abstract}
Abstrak
Penelitian ini bertujuan untuk mengungkapkan secara mendalam tentang penerapan penjaminan mutu eksternal di SDIT Sabilul Huda. Penelitian ini menggunakan pendekatan kualitatif deskriptif. Teknik pengumpulan data dilakukan secara trianggulasi, analisis data bersifat induktif penjaminan mutu eksternal secara rinci dan akurat melalui hasil data yang berasal dari data tertulis dan dokumentasi dan wawancara lisan dari orang-orang terkait. Hasil penelitian menunjukkan bahwa penerapan penjaminan mutu eksternal di SDIT Sabilul Huda dapat dikatagorikan cukup baik, yaitu pada standar kompetensi lulusan, standar isi kurikulum, standar proses, standar pendidik dan tenaga pendidik, standar sarana dan prasarana, standar pengelolaan satuan pendidik, standar pembiayaan pendidikan dan standar penilaian.
\end{abstract}

Kata kunci : standar mutu, penilaian, eksternal 


\section{PENDAHULUAN}

Penjaminan mutu dalam dunia pendidikan, memang harus ditingkatkan mengingat mutu pendidikan di Indonesia pada khususnya jauh dari apa yang diharapkan. Kita juga mengetahui bahwa sekolah-sekolah baik dari tingkat dasar, menengah maupun atas tentang kondisi sarana prasarana dan proses pembelajaran kurang memuaskan sehingga penjaminan mutu pendidikan merupakan program yang utama bahkan sangat amat penting bagi menteri pendidikan bahkan bagi pemerintah. Penjaminan mutu pendidikan itu sendiri merupakan kegiatan mandiri oleh lembaga pendidikan tertentu. Oleh karena itu harus disusun, dirancang dan dilaksanakan sendiri. Salah satu upaya dalam merealisasikan penjaminan mutu tersebut dapat dilakukan secara bertahap oleh pihak sekolah, yakni dengan melakukan evaluasi diri, kemudian ditindaklanjuti dengan monitoring sekolah oleh pihak pemerintah daerah, sehingga sistem penjaminan mutu pendidikan dapat dilakukan dengan baik.

Sistem penjaminan mutu yang efektif di lembaga pendidikan akan memberikan dampak positif baik secara langsung maupun tidak langsung. Laporan Bank Dunia memperlihatkan pentingnya penjaminan mutu dan sangat berdampak kepada banyak faktor, yakni mobilitas staf dan siswa, kebebasan manajemen program akademik, penciptaan jenis baru lembaga pendidikan, di mana pendidikan melampaui batas-batas standar nasional yang sudah ditentukan (Bernhard, 2012)

Sistem penjaminan mutu lazimnya dilakukan melalui kegiatan audit yang ketat yang berdampak secara langsung maupun tidak langsung. Dampak langsungnya, yaitu transparansi, peningkatan status, pembelajaran efektif, dan integrasi sosial lembaga. Sedangkan dampak tidak langsung hanya muncul, yakni motivasi, hubungan baik di kalangan organisasi dan lain-lain. Selanjutnya Haapakorpi menjelaskan bahwa struktur dan manajemen organisasi, disiplin individu, dan budaya berpengaruh terhadap hasil penjaminan mutu (Haapakorpi, 2011).

Sistem penjaminan mutu pendidikan dasar dan menengah terdiri atas dua komponen yaitu Sistem Penjaminan Mutu Internal (SPMI) dan Sistem Penjaminan Mutu Eksternal (SPME) (Direktorat Kementerian Pendidikan Dasar dan Menengah, 2016: 1617). Sistem Penjaminan Mutu Internal adalah sistem penjaminan mutu yang dilaksanakan dalam satuan pendidikan dan dijalankan oleh seluruh komponen satuan pendidikan. Sistem Penjaminan Mutu Eksternal yaitu sistem penjaminan mutu yang dilaksanakan oleh pemerintah, pemerintah daerah, lembaga akreditasi dan lembaga standarisasi pendidikan;

Penjaminan mutu pendidikan dasar dan menengah adalah suatu mekanisme yang sistematis, terintegrasi, dan berkelanjutan untuk memastikan bahwa seluruh proses penyelenggaraan pendidikan telah sesuai dengan standar mutu dan aturan yang ditetapkan. Untuk dapat melakukan penjaminan mutu pendidikan dengan baik diperlukan adanya sistem penjaminan mutu pendidikan.

Data Mutu Eksternal Akreditasi Akreditasi sebagai penjaminan mutu eksternal memilki data mutu. Sebelum lanjut dilihat dulu pengertian akreditasi. Akreditasi berasal dari bahasa Inggris yaitu "to accredite "yang artinya adalah meniulia kelayakan teknis / akademis suatu lembaga penyelenggara program pendidikan tertetnu untuk menghasilkan lulusan dengan spesifikasi kompetensi yang telah ditetapkan. Akreditasi sekolah atau madrasah merupakan penilaian yang menyeluruh terhadap sekolah sebagai bentuk akuntabilitas publik (Kemendikbud, 2017).

Dikatakan menyeluruh karena akreditasi menilai kelayakan sebuah sekolah/ madrasah pada semua standar 8 dari 8 Standar Nasional Pendidikan. Badan Akreditasi Nasional (BAN) Sekolah/ Madrasah melakukan analisis data ketika melakukan akreditasi, otomatis

Ali Hasan. Vol. 5 No. 2 ISSN 2549-0877 
akreditasi memiliki data mutu berupa perangkat instrument ynag sudah diverifikasi, catatan temuan visitasi dan rekomendasi perbaikan (Kemendikbud, 2017). Data mutu ini diisi dengan prinsip-prinsip kejujuran, objektif, efektif, komprehensif, mandiri, berbasis kesiapan (Permendikbud No 13: 2).

Adapun ruang lingkup akreditasi meliputi: TK / RA, TKLB, SD/MI, SMP / MTs, SMPLB, SMA / MA, SMK/ MAK, dan SMA LB baik sekolah negeri maupun swasta. Manfaat Data Mutu Sebagai kontrol mutu eksternal (salah satu bagian dari SPME) tentu akreditasi memberikan manfaat yang signifikan bagi sekolah/ madrasah. Manfaat tersebut antara lain: (1) Membantu sekolah / madrasah dalam menentukan dan mempermudah kepindahan peserta didik dari suatu sekkolah ke sekolah lain, pertukaran guru, dan kerjasama yang saling menguntungkan. (1) Misalnya, sekolah yang berakreditasi A hanya dapat menerima siswa pindah dari sekolah yang berarkreditasi A; (2) Membantu mnegidentifikasi sekolah / madrasah dan program dalam rangka pemberian bantuan oleh pemerintah, swasta, atau donatur lainnya; (3) Acuan dalam peningkatan mutu sekolah / madrasah dan rencana pengembangan sekolah / madrasah; (4) Umpan balik dari SPMI sekolah sebagai sebuah hasil kerja keras sehingga dorongan baagi guru untuk selalu meningkatkna diri; (5) Motivator agar sekolah dapat meningkatkna mutu pendidikan secara bertahap, terencana, dan kompetitif baik tingkat kabupaten, provinsi, nasional dan bahkan internasional; (6) Sebagai data mutu sekolah baik bagi sekolah, pemerintah dan masyarakat dalam rangka peningkatan mutu; (7) Bagi siswa dapat meningkatkan kepercayaan diri bahwa mereka dapat pendidikan yang layak (Kemendikbud, 2016).

Oleh karena itu kami ingin mengetahui sejauhmana implementasi sistem penjaminan mutu yang telah dilakukan di SDIT Sabilul Huda Kota Cirebon. Penelitian ini termasuk penelitian lapangan (Field Research). Penelitian lapangan adalah penelitian yang dilakukan di suatu tempat atau lokasi yang dipilih untuk meneliti atau menyelidiki sesuatu yang terjadi di tempat tersebut (Fathoni, 2006: 96).

Penelitian ini dimaksudkan untuk mengidentifikasi dan menganalisis implementtasi sistem penjaminan mutu eksternal di SDIT Sabilul Huda Kota Cirebon. Dari total 103 sekolah dasar dan menengah yang ada di Kota Cirebon (Data Referensi Kementerian dan Kebudayaan Kota Cirebon) peneliti memilih SDIT Sabilul Huda Kota Cirebon sebagai objek penelitian di karenakan sekolah ini tergolong perkembangannya sangat pesat di Kota Cirebon dan memiliki kualitas mutu pendidikan yang baik. Terbukti sejak didirikan tahun 2002, SDIT Sabilul Huda telah mengalami kemajuan yang signifikan, dengan prestasi terakreditasi A (Amat Baik) (Dokumen Profil SDIT Sabilul Huda Kota Cirebon, 2020) sampai kemarin proses akreditasi yang dilakukan oleh BAN-S/M di SDIT Sabilul Huda Kota Cirebon berhasil mendapatkan Nilai 95 (A) yang dilaksanakan pada tanggal 27-28 November 2019 (Apriliani, 2019).

\section{METODE}

Pendekatan penelitian ini menggunakan pendekatan kualitatif dengan jenis penelitian deskriptif yaitu dengan menyajikan analisis mengenai keadaan atau penerapan inovasi kurikulum secara rinci dan akurat melalui hasil data deskriptif yang berasal dari data tertulis dan wawancara lisan dari orang-orang terkait (Afrizal, 2016). Metode penelitian kualitatif dapat diartikan sebagai metode penelitian yang digunakan untuk meneliti pada kondisi objek yang alamiah, dimana peneliti sebagai instrumen kunci, teknik pengumpulan data dilakukan secara trianggulasi (gabungan), analisis data bersifat induktif, hasil penelitiannya lebih menekankan makna dibanding generalisasi (Sugiyono, 2015).

Kajian yang dimaksud adalah penelitian menggunakan pendekatan kualitatif dengan jenis penelitian deskriptif dengan menyajikan analisis mengenai implementasi sistem 
penjaminan mutu eksternal secara rinci dan akurat melalui hasil data yang berasal dari data tertulis dan dokumentasi dan wawancara lisan dari orang-orang terkait.

\section{TEMUAN DAN PEMBAHASAN}

Riset mutakhir menunjukkan bahwa ada kecenderungan yang kuat diakibatkan oleh diterapkannya sistem penjaminan mutu di pendidikan di Eropa terhadap penguatan mutu pendidikan. "Audit kelembagaan" atau "audit mutu" merupakan kebijakan dan sistem yang paling banyak dipakai sebagai instrumen penjaminan kualitas (Corengia, et al., 2014)

Implementasi penjaminan mutu di SDIT Sabilul Huda melalui beberapa standar, yaitu standar kompetensi lulusan, standar isi, standar proses, standar penilaian, standar pendidik dan tenaga kependidikan, standar pengelolaan, standar sarana dan prasarana, dan standar pembiayaan. Dalam pelaksanaan masingmasing standar berjalan dengan baik.

1. Implementasi standar kompetensi lulusan Di SDIT Sabilul Huda sangat baik. Hal ini dibuktikan dengan adanya peningkatan prestasi baik akademik, ekskul, seni, keagamaan pada setiap tahunnya. Berdasarkan hasil wawancara yang saya lakukan dengan Ibu YA, beliau mengungkapkan:

"Alhamdulillah setiap tahunnya kami selalu mendapatkan prestasi-prestasi yang didapatkan oleh anak-anak kami. Yamg terdekat adalah di bidang ekskul kami mendapatkan perak dan perunggu dalam cabang olahraga panahan dalam kejuaraan POP Kota Cirebon, Juara 2 membacakan dongeng sunda, beberapa kali menjuarai olahraga taekwondo dan masih banyak lagi lainnya"(wawancara dengan Ak 11 November 2020)

SDIT Sabilul Huda mempasilitasi berbagai kegiatan untuk memotivasi siswa dalam berbagai aspek baik itu perilaku, karakter, minat, bakat dan potensi yang dimiliki oleh siswa. Ini semua di buktikan dengan banyaknya intrakulikuler atau pun ekstra kulikuler yang ada di sekolah ini diantaranya Pramuka, Silat, taekwondo, seni, qiroati, dan masih banyak lagi yang lainnya (dokumen standar lulusan).

2. Implementasi standar isi mengenai kurikulum

Kurikulum yang dipakai SDIT Sabilul Huda menggunakan kurikulum 2013 dimulai tahun pelajaran 2013/2014 (wawancara YA 12 Desember 2020). SDIT Sabilul Huda mendapatkan kepercayaan dari Diknas Kota Cirebon dan Pemprov Jawa Barat untuk menjadi sekolah pilot proyek penelitian dan pengembangan model pendidikkan kurikulum 2013.

Kurikulum merupakan inti dari sebuah lembaga pendidikan, dan SDIT Sabilul Huda adalah sekolah yang menggunakan kurikulum 2013 dengan kurikulum khas SDIT Sabilul Huda yang mencakup nilai-nilai keislaman meliputi: (1) Pendidikan Agama: Aqidah, Ibadah, Akhlak, Tahsin \& Tahfidz Qura'an; (2) Bahasa: Indonesia, Arab, Inggris, Cirebon dan Sunda; (3) Seni dan daya cipta: Seni Rupda, Musik dan Gerak; (4) Sains dan Teknologi: Sains dan Komputer (Pembelajaran multimedia); (5) Pendidikan Jasmani: Olahraga dan Kesehatan; (6) Pendidikan lingkungan: Field Trip / study tour, kemah; (7) Keterampilan dan Wirausaha: Keterampilan dan bisnis (koperasi sekolah); (8) Outbond; (dokumen profil sekolah).

Seperti yang telah disampaikan diatas dalam standar isi ini SDIT Sabilul Huda dalam proses akreditasi mampu menunjukkan bukti fisik dalam mengembangkan kurikulum pembelajaran dari perangkat pembelajaran sesuai dengan tingkat kompetensi sikap spiritual di SD/MI, sikap sosial di SD/MI, pengetahuan, keterampilan (dokumen standar isi).

Berdasarkan pemaparan bapak Sp dalam pelaksanaan kurikulum di SDIT Sabilul Huda dilakukan melalui pembelajaran dengan pendekatan tematik-terpadu dari kelas I sampai VI, sedangkan mata pelajaran Pendidikan agama dan Budi pekerti di kecualikan (wawancara Sp 1 Desember 2020). Dapat 
dibuktikan dari perangkat pembelajaran tematik Terpadu pada setiap kelas setiap semester dan silabus maupun RPP pembelajaran tematik terpadu pada semua tingkat kelas dan sesuai dengan buku guru maupun siswa (dokumen standar isi).

3. Implementasi Pelaksanaan standar proses

Di SDIT Sabilul Huda Kota Cirebon sudah berjalan dengan baik. Hal ini dapat dilihat dari penerapan sistem manajemen di sekolah tersebut yang semua ditangani dan diawasi oleh kepala sekolah secara langsung dan dalam perencanaan pembelajaran sesuai dengan prosedur yang diterapkan. Dilihat dari RPP kurtilas yang berfokus pada keaktifan siswa, guru mampu membawa suasana belajar menjadi aktif kreatif dan mengasyikan di dalam proses pelaksanaan KBM sehingga pengelolaan kelas baik dan dengan jumlah siswa perkelas paling banyak $27-28$ orang (dokumen profil SDIT Sablul Huda).

Dilihat dari kelengkapan dokumen yang di tunjukkan oleh pihak sekolah, misalkan dari kelengkapan komponen dan isi silabus, komponen RPP yang lengkap dari mulai identitas sekolah sampai penilaian hasil pembelajaran, begitupun dalam jadwal pembelajaran, kalender akademik pembagian tugas guru dan tugas tambahan lainnya (dokumen standar proses). Setiap satu tahun sekali dilaksanakan evaluasi sehingga dalam melaksanakan proses pembelajaran semakin baik (wawancara YA 2 Desember 2020). Ini senada dengan apa yang dipaparkan oleh bapak Sp dan beliau mengungkapkan:

"SDIT Sabilul Huda mewajibkan pada setiap guru untuk melengkapi administrasi pembelajaran di awal tahun pembelajaran baik itu dari silabus, RPP, prota, promes dan lain-lainnya, supaya kami dari bidang kurikulum bisa mengevaluasi jikalau masih ada kekurangan-kekurangan dari administrasi yang telah guru buat sehingga kami bisa mengembalikan kepada para guru untuk dapat mereka perbaiki." (wawancara dengan Sp 2 Desember 2020)
Sp menambahkan:

"Tapi untuk tahun sekarang kami dari pihak sekolah mewajibkan setiap guru untuk menyerahkan RPP yang mereka buat sebelum mulai KBM untuk di periksa kepala sekolah dan di tanda tangani oleh kepala sekolah" (wawancara dengan Sp 3 Desember 2020)

4. Implementasi standar pendidik dan tenaga pendidik

Mengenai perekrutan tenaga pendidik sudah berjalan dengan baik. Dalam pelaksanaan perekrutan tenaga pendidik dan tenaga kependidikan dilaksanakan secara mandiri oleh pihak sekolah yang melalui beberapa proses seleksi, dengan masa percobaan 6 bulan. Adapun tahapan-tahapan yang dilakukan antara lain: tes tulis, baca alQur'an, peer teaching, dan wawancara. Semua guru di SDIT Sabilul Huda Kota Cirebon telah mempunyai 4 kompetensi yaitu pedagogik, kepribadian, sosial, professional (wawancara dengan YA 30 November 2020).

Kalau di lihat dari standar pendidik dan tenaga pendidik SDIT Sabilul Huda masih kurang baik, ini dapat dilihat dari persebaran tenaga kerja yang ada di sana masih banyak yang tidak sesuai denga ijazahnya dan masih sedikit sekali guru yang sudah tersertifikasi, contoh di lembar ijazahnya dia lulusan S1 Matematika tp dia sebagai pengajar Qiroati. Seperti yang di ungkapkan bapak Sp, yakni:

"untuk standar pendidik dan tenaga pendidik kami masih mendapatkan nilai yang kecil dari tujuh standar lainnya, itu dikarenakan guru di kami masih belum semuanya linier sesuai dengan ijazah terakhir yang di dapat dan masih sedikitnya guru-guru di kami yang bersertifikasi"(wawancara Sp 15 Desember 2020).

Untuk standar pendidik dan tenaga pendidik walau pun mendapatkan nilai yang kecil dari tujuh standar lainnya menurut penulis itu tidak jadi masalah karena dalam penilaian 
standar ini bukan di lihat dari selembar ijazah dan sertifikat guru saja melainkan guru juga mampu mengaplikasikan RPP yang dibuat saat KBM dan mampu melakukan PTK sebagai evaluasi dan membuat inovasi baru dalam kegiatan belajar mengajar. maka dari itu walau pun di standar ini SDIT Sabilul Huda mendapatkan nilai yang kecil tapi masih mendapatkan nilai di angka delapan puluh lima.

5. Implementasi standar sarana dan prasarana

Implementasi standar sarana dan prasarana sudah baik. Hal ini dapat dilihat dari setiap bangunan yang kokoh, perangkat pencegahan bahaya kebakaran, penengkal petir ada di SDIT Sabilul Huda (wawancara Yn 1 Desember 2020). Penyediaan sarana prasarana melalui anggaran sekolah, jika ada sarana maupun prasarana yang harus diperbaiki maka pihak sekolah akan mendatangkan ahli yang mampu memperbaiki sarana tersebut. Jika sarana tersebut tidak dapat diperbaiki maka dapat diganti dengan sarana yang baru. Dalam pelaksanaannya disesuaikan dengan anggaran sekolah. Jadi pihak sekolah sendiri akan memilih dan memilah mana yang lebih penting dan yang harus diutamakan.

Hal ini dibuktikan SDIT Sabilul Huda Kota Cirebon menjadi juara bintang kantin sehat se-Jawa Barat (Yn 3 Desember 2020). Diatas tanah seluas $1995 \mathrm{~m}^{2}$, dan luas bangunan $1692 \mathrm{~m}^{2}$ dengan dua lantai dan tiga belas rombongan belajar dengan siswa sebanyak kurang lebih 324 orang sudah sangat layak untuk level SD/MI (dokumen standar sarana prasarana). SDIT Sabilul Huda diantaranya meliki: ruangan kelas; ruang guru, ruang pimpinan, ruang perpustakaan, ruang laboratorium, kantin, tempat parker, gudang, toilet, musola/masjid, tempat bermain/olah raga dan UKS. Semuanya memiliki fasilitas dan kelengkapan ruangan yang memadai (dokumen standar sarana prasarana).

Menurut pemaparan bapak Sp yakni:

"Untuk standar sarana dan prasarana sekolah kami mendapatkan nilai yang sangat baik, kenapa? Karena dari standar yang di berikan sekolah kami sudah layak, itu dibuktikan dengan bangunannya yang kokoh serta perlengkapan setiap ruangan yang sudah terpenuhi baik dari ruang kelas, guru, perpustakaan, kantin, masjid, lahan parker, lapangan upacara, aula semuanya juga memiliki standar pentilasi udara yang baik sehingga ruangan tidak pengap anakanak menadi nyaman belajar." (dokumen standar sarana prasarana)

\section{Impelementasi standar pengelolaan} menganai satuan pendidik

SDIT Sabilu Huda memiliki visi yakni "Unggul dalam Prestasi Akademik Berbasis Karakter dan Moral Islam" dan memiliki misi: (a) Melaksanakan kegiatan pembelajaran dengan optimal berpedoman pada kurikulum pendidikan nasional dan kurikulum khas yang matang dengan daya dukung SDM yang kompeten di bidangnya; (b) Menggali dan membimbing setiap siswa untuk mengenali potensi dirinya untuk dapat dikembangkan secara optimal; (c) Menciptakan budaya berprestasi dan unggul dalam setiap melakukan aktivitas di lingkungan sekolah; (d) Menumbuhkan semangat dan kesadaran untuk senantiasa berkomitmen dengan ajaran Islam sebagai upaya pembentukan lingkungan sekolah yang bernuansa Islam tinggi; (e) Melibatkan seluruh komponen sekolah dan komite sekolah dalam menentukan kebijakan strategis sekolah (dokumen profil SDIT Sabilul Huda); kalender pendidikan, struktur organisasi sekolah, tata tertib sekolah, kode etik sekolah, pembagian tugas antar guru semuanya sudah di atur dalam sebuah system (dokumen standar pengelolaan).

Guru tidak hanya menyampaikan materi saja tetapi juga mendidik melainkan menanamkan karakter-karakter bagi siswa sehingga siswa memiliki karakter yang kuat dalam setiap pilihan yang akan dihadapinya. Pembinaan karakter ini di berikan pada anak kelas 4,5 dan 6 dengan program BPI (Bina Pribadi Islam) sedangkan program pada anak kelas 1, 2 dan 3 adalah Calistung (Baca Tulis Hitung). Kepala 
sekolah juga melakukan supervisi yang dilaksanakan per tiga bulan sekali pada guru (wawancara Yp 20 November 2020).

Senada dengan apa yang di ungkapkan bapak Sp:

"Dalam pengelolaan menganai satuan pendidik dari penerimaan siswa baru, melakukan bimbingan konseling baik oleh wali kelas atau pun guru BK, kegiatan ekstra kulikuler wajib atau pun pilihan, pembinaan prestasi itu semua di birikan untuk mengembangkan bakat dan minat anak dan memiliki karakternya masingmasing. Menanamkan karakter-karakter pada siswa sehingga siswa memiliki karakter yang kuat dalam setiap pilihan yang akan dihadapinya. Pembinaan karakter ini di berikan pada anak kelas 4, 5 dan 6 dengan program BPI (Bina Pribadi Islam) sedangkan program pada anak kelas 1,2 dan 3 adalah Calistung (Baca Tulis Hitung)"

\section{Implementasi standar pembiayaan pendidikan}

Di SDIT Sabilul Huda Kota Cirebon sudah berjalan dengan baik. hal ini dapat dilihat dari sumber pembiayaan di SDIT Sabilul Huda Kota Cirebon didapatkan melalui 2 sumber yang diantaranya, pembiayaan yang berasal dari pemerintah pusat melalui dana BOS, dan dari iuran pendidikan yang diterapkan dari mulai kelas $1-6$. Dalam pengelolaan keuangan di SDIT Sabilul Huda Kota Cirebon yang bertanggung jawab adalah kepala sekolah dan bendara sekolah (wawancara Ya 2 Desember 2020).

Bapak Sp menyabutkan:

"Biaya yang kami peroleh melalui 2 sumber yang diantaranya, pembiayaan yang berasal dari pemerintah pusat melalui dana BOS, dan dari iuran pendidikan yang diterapkan dari mulai kelas $1-6$. Dari dua sumber pembiayaan ini $\mathrm{kmi}$ alokasikan untuk diantara biaya untuk biaya pengebangan pendidik dan tenaga kependidikan seperti (pelatihan, seminar, dan lain-lainya), biaya modal kerja (untuk seluruh kebutuhan pendidikan), gaji guru, biaya alat tulus sekolah, biaya bahan habis pakai (penghapus, sepidol, penggaris, kertas, dll), biaya pemeliharaan dan perbaikan berkala, dan masih banyak lainnya."

8. Implementasi standar penilaian

Hasil belajar yang dilaksanakan oleh SDIT Sabilul Huda Kota Cirebon adalah sesuai dengan ketentuan yang ditentukan oleh kurikulum. Evaluasi penilaian kurikulum 2013 yang lebih diutamakan adalah penilaian karakter/penilaian afektif (wawancara Ya 2 Desember 2020). KKM setiap mata pelajaran ditentukan oleh satuan pendidikan dengan mempertimbangkan: (a) karakteristik kompetensi dasar yang akan di capai; (b) daya dukung (sarana pembelajaran dan kualitas guru); (c) karakteristik siswa.

Seperti bapak Sp menyebutkan:

"Dalam KKM setiap mata pelajaran/tema ditentukan oleh satuan pendidikan dengan pertimbangan; 1) karakteristik KD yang akan dicapai; 2) daya dukung (sarana pembelajaran dan kualitas guru); 3) karakteristik siswa. Selain dari itu guru juga memberikan penilaian ulangan harian pada siswa, pengamatan/observasi atau pun penugasan lainnya. Di sekolah kami juga guru menggunakan hasil kompetensi pengetahuan untuk: 1) memperbaiki proses pembelajaran; 2) mengukur dan mengetahui pencapaian kompetensi siswa; 3) menyusun laporan kemajuan hasil belajar harian" (wawancara dengan Sp 2 Desember 2020).

Penerapan tahapan sistem penjaminan mutu di SDIT Sabilul Huda tercapai jika dukungan oleh top manajemen dan melaksanakan banyak stakeholder kerja sama dengan lembaga pendidikan lainnya. Kesemuanya itu sebagaimana dikatakan oleh Seyfried \& Pohlenz (2018) dapat menjadikan ketercapaian keberhasilan implementasi penjaminan mutu. Selanjutnya untuk mempertahankan penjaminan mutu dibutuhkan konsep yang betul-betul bisa diterima oleh 
seluruh pihak. Beberapa hasil penelitian memperlihatkan bahwa budaya mutu menjadi pemecahan masalah penting untuk meningkatkan mutu lembaga pendidikan (Hildesheim \& Sonntag, 2020; Yingqiang \& Yongjian, 2016). Budaya mutu memfokuskan kepada komitmen terhadap mutu, adanya sikap bersama, dan pentingnya peningkatan mutu yang berkelanjutan (Dzimińska et al., 2018).

\section{SIMPULAN}

\section{DAFTAR PUSTAKA}

Afrizal. (2016). Metode penelitian kualitatif: Sebuah upaya mendukung penggunaan penelitian kualitatif dalam berbagai disiplin ilmu. Jakarta: PT Raja Grafindo Persada.

Bernhard, A. (2012). Quality assurance in an international higher education area. Wiesbaden: VS Verlag für.

Corengia, Á., Del Bello, J. C., Pita Carranza, M., \& Adrogué, C. (2014). Quality assurance systems of higher education The case of European institutions: Origin, Evolution and Trends. Revista Gestão Universitária Na América Latina - GUAL, 7(3), 61-76.

Data Referensi Kementerian dan Kebudayaan Kota Cirebon (https://referensi.data.kemdikbud.go.id/i ndex11.php?kode=026304\&level=3), diakses 11 Maret 2021.

Direktorat Kementerian Pendidikan Dasar dan Menengah. (2016). Pedoman umum sistem penjaminan mutu pendidikan dasar dan menengah. Jakarta: Kementerian Pendidikan dan Kebudayaan
Untuk memperoleh pendidikan yang berkualitas maka SDIT Sabilul Huda melaksanakan berbagai proses penjaminan mutu secara eksternal pada semua standar mutu yang ditetapkan oleh pemerintah. Proses ini juga merupakan bahan evaluasi mengenai apa yang belum diwujudkan dan yang mesti dipertahankan. SDIT Sabilul Huda seyogyanya bekerjasama dengan semua stakeholder untuk bisa memberikan hasil terbaik.

Dzimińska, M., Fijalkowska, J., (2018). TrustBased Quality Culture Conceptual Model for Higher Education Institutions. Sustainability, 10(8):2599. DOI:10.3390/su10082599

Fathoni, A. (2006). Metodologi penelitian dan teknik penyusunan skripsi. Jakarta: PT. Rineka Cipta.

Haapakorpi, A. (2011). Quality Assurance Processes in Finnish Universities: Direct and Indirect Outcomes and Organisational Conditions. Quality in Higher Education, 17(1), 69-81. https://doi.org/10.1080/13538322.2011. 554311

Hildesheim, C., \& Sonntag, K. (2020). The quality culture inventory: A comprehensive approach towards measuring quality culture in higher education. Studies in Higher Education, 45(4), 892-908. https://doi.org/10.1080/ 03075079.2019.1672639

Kemendikbud. (2016). Tentang Manfaat Data Mutu Sebagai kontrol mutu eksternal

Kemendikbud. (2017). Permendikbud No 13: 2018.

Sugiyono. (2015). Metode penelitian metode komperhensif. Bandung: Alfabeta.

Yingqiang, Z. \& Yongjian, S. (2016). Quality assurance in higher education: Reflection, criticism, and change. Chinese Education \& Society, 49(1-2), 7-19. 
https://doi.org/10.1080/10611932.2016.

1192382

Ali Hasan. Vol. 5 No. 2 ISSN 2549-0877 